\title{
High spring temperatures decrease peach fruit size
}

by Gerardo Lopez, R. Scott Johnson

and Theodore M. DeJong

\section{The growth and productivity of} peach fruit can be limited by many factors, including weather. Previous research indicated that early-spring temperatures for 30 days after bloom have a strong effect on early peach fruit growth, and both the time and potential fruit size at harvest. We analyzed fruit-size trends of three major cultivars in the California freshmarket peach industry (Flavorcrest, Elegant Lady and O'Henry) over a 20-year period to determine if there is a clear relationship between earlyspring temperatures and packed fruit sizes industrywide. This research confirmed two significant trends: the size of packed fruit has increased over the 20-year period between 1985 and 2004, and high early-spring temperatures tended to decrease the size of packed fruit at harvest for any given year.

$\bigcirc$ ver the past few decades, models of peach fruit growth and plant development have identified useful principles for assisting growers in making horticultural management decisions. For example, harvest-date prediction models are now available to aid in managing fruit crops (Ben Mimoun and DeJong 1999). The unusually early harvest of California's peach crop in 2004 - which had record high temperatures during bloom time - and attendant difficulties in attaining the fruit sizes desired by the market (DeJong 2005) have increased interest in using physiological concepts to understand the effects of early-spring temperature on peach fruit growth and in anticipating fruit size at harvest.

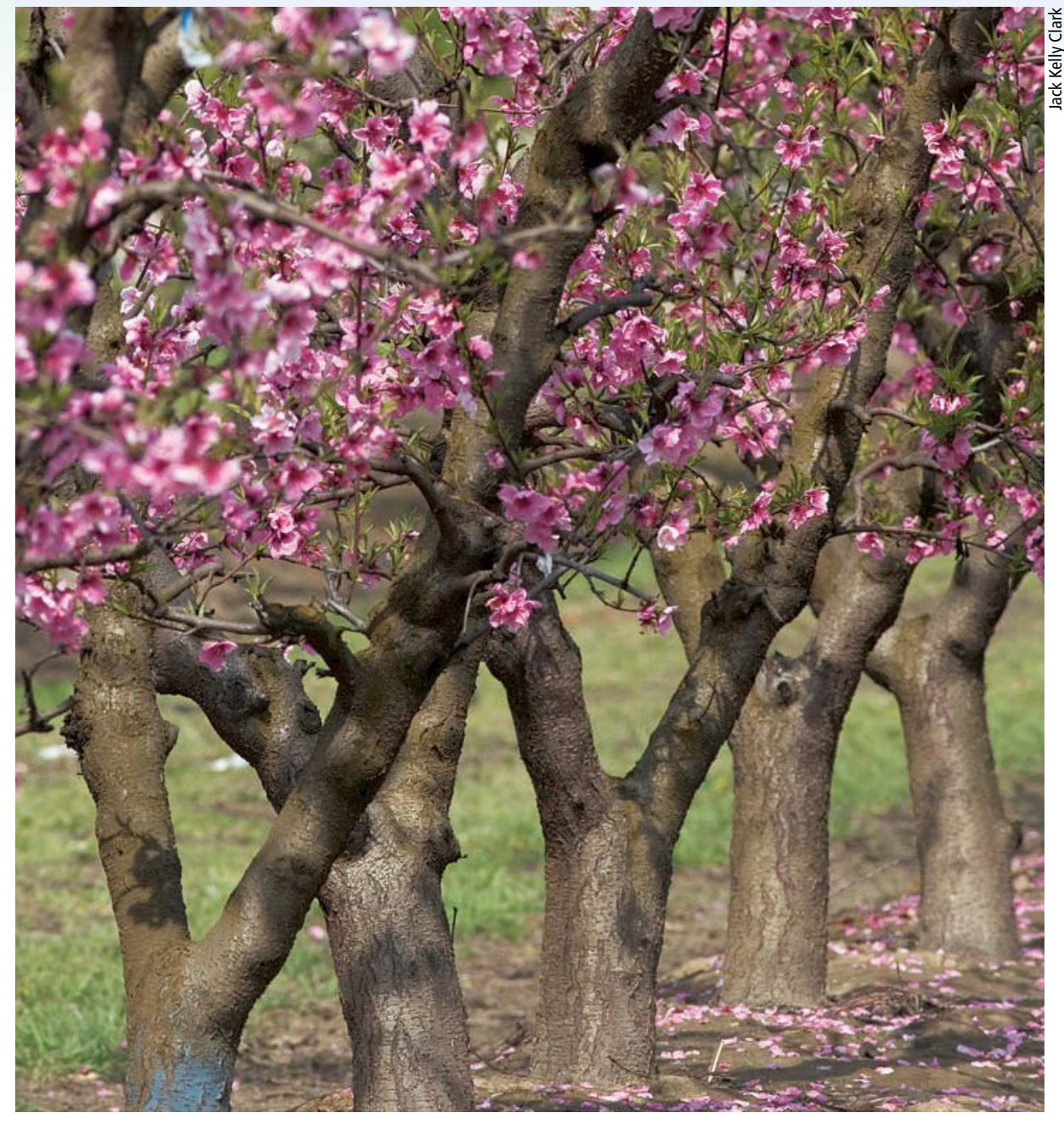

An analysis of fruit-size and weather data quantified trends over 20 years in the California peach industry. Temperatures during the $\mathbf{3 0}$ days after peach trees bloom can have a strong influence on the size of fruit at harvest.

The dependence of peach fruit development on spring temperatures during the first 30 days after bloom has been established; there is a strong correlation between the sum of growing degreehours accumulated in the 30 days after bloom $\left(\mathrm{GDH}_{30}\right)$ and the number of days between bloom and harvest for several stone-fruit cultivars (Ben Mimoun and DeJong 1999).

Traditionally, the California clingstone peach industry has used reference-date fruit size (the size of fruit at the date of pit-tip hardening, plus 10 days) to predict what the fruit size potential will be for a given year, and then peach growers conduct fruit-thinning accordingly. Reference-date fruit sizes are known to vary from year to year, but the rea- sons for this variation were previously unclear. Lopez and DeJong (2007) compared a 20-year clingstone-peach data set collected and archived by the California Canning Peach Association, which included full bloom date (FBD), reference date (RD) and fruit size (FS) at reference date from different locations in California.

When the data - collected from orchards near the Central Valley cities of Kingsburg, Modesto and Yuba City - was correlated with seasonal weather data available through the California Irrigation Management Information System (CIMIS), a strong correlation was found between accumulated $\mathrm{GDH}_{30}$ and the number of days between full bloom date and 


\section{High early-spring temperatures tend to decrease the average size of fruit packed in a given year.}

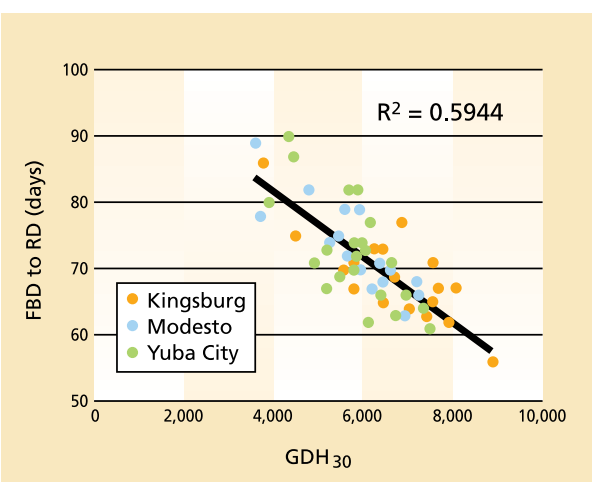

Fig. 1. Accumulated growing degree-hours 30 days after bloom $\left(\mathrm{GDH}_{30}\right)$ and number of days between full bloom and reference date (FBD to RD) in canning clingstone peaches grown in three California regions (adapted from Lopez and DeJong 2007).

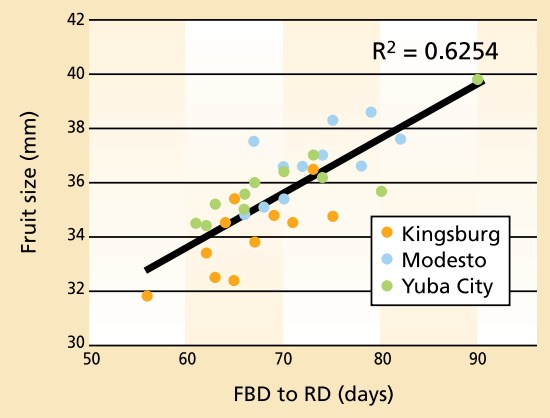

Fig. 2. Days from full bloom to reference date (FBD to RD) and peach fruit size at reference date in canning clingstone peaches grown in three California regions (adapted from Lopez and DeJong 2007).

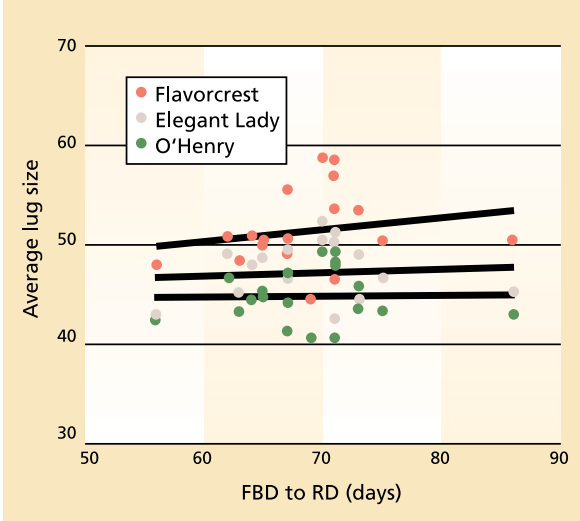

Fig. 3. Days from full bloom to reference date (FBD to RD) for the Kingsburg area, available from the canning clingstone peach industry, and average fruit-size lug at harvest in freshmarket freestone peaches. reference date (fig. 1). The number of days between full bloom date and reference date decreased as accumulated $\mathrm{GDH}_{30}$ increased (fig. 1). There was also a strong correlation between the number of days from full bloom date to reference date, and fruit size at reference date. Fruit size at reference date increased with an increase in the number of days from full bloom date to reference date (fig. 2). This study indicated that peach trees apparently could not supply resources rapidly enough to support the potential maximum fruit growth rates when accumulated $\mathrm{GDH}_{30}$ was higher than a threshold value $(\sim 5,700 \mathrm{GDH})$. Consequently, fruit size at reference date in years with very warm spring temperatures was less than in years when accumulated $\mathrm{GDH}_{30}$ was below that threshold value. Furthermore, previous research has documented that fruit growth potential unfulfilled in early spring cannot be compensated for later in the season (Grossman and DeJong 1995b).

\section{Analysis of fruit-size trends}

Although the effects of early-spring temperature on fruit size have been quantified for clingstone peaches at reference date, and fruit size at reference date is thought to be a good indicator of fruit size at harvest, industrywide data on fruit size at harvest is not available from the canning clingstone peach industry. However, the industrywide data situation is the opposite for California freshmarket peaches. This industry does not keep representative seasonal data on full bloom date or reference date, but general fruit-size data is available from industry records maintained by the California Tree Fruit Agreement (CTFA). At the outset of this study, we anticipated that the environmental factors influencing fruit growth and development rates for canning clingstone peaches would be the same as for fresh-market freestone peaches. Thus we initiated a follow-up study using relationships we had established for clingstone peaches to analyze the seasonal environmental effects on industrywide data for the fruit size of freestone peach cultivars.
When fresh-market peaches are packed for shipping, the fruit are separated into different size categories related to the number of fruit that will fit into a standard-size lug box. Fruit packed in a size 30 lug are larger than those in a size 40 lug, while the fruit in a size 40 lug are larger than those in a size 50 lug, and so on. The CTFA annually reports the percentage of the total number of lugs for specific fruit-size categories (\% lug size) that are shipped for each major cultivar at harvest.

Data from three different freshmarket peach cultivars (Flavorcrest, Elegant Lady and $\mathrm{O}^{\prime}$ Henry) were used for this study (California Tree Fruit Agreement annual reports from 1985 to 2004) and compared with full bloom and fruit reference-date data for clingstone canning peach cultivars (figs. 1 and 2). However, the average fruitsize lug category of the fresh-market cultivars was not correlated with the number of days between full bloom date and reference date for the clingstone cultivars in a given year in the Kingsburg area (fig. 3).

When we analyzed historical trends in fruit size, there was a clear trend toward lower average lug categories; over the 20 years of this study, the average size of the fruit packed for each cultivar increased significantly (fig. 4). Although improvements in cultural practices may account for some of the increases in packed fruit size, this long-term trend presumably can be attributed to marketing pressures. Consumer acceptance of California peaches has been related to soluble solid concentration, acidity or soluble solid concentration/acidity ratio, but the major quality factor is fruit appearance (Crisosto et al. 1995, 1997). Likewise, market pricing has consistently favored larger-sized fruit.

The percentage distribution trends of average fruit-size categories over the 20 years were similar for the three cultivars, and there were no significant differences in the slope of the regressions between Elegant Lady and O'Henry, or between Elegant Lady and Flavorcrest. However, the slope of the response for Flavorcrest was steeper than for $\mathrm{O}^{\prime}$ Henry (fig. 4). 
When the effect of the year on the percentages of four fruit-size lug categories at harvest (30s, 40s, 60s and 80 s) was analyzed independently, different patterns were observed among the cultivars and categories (fig. 5). Although all the cultivars increased the percentages of larger fruit-size lug categories (30s and 40s) and decreased the percentages of the smaller fruitsize lug categories (60s and 80s), the slopes of the 30s and 80s categories of Flavorcrest relationships were clearly different from those of Elegant Lady and $\mathrm{O}^{\prime}$ Henry (fig. 5).

The change in Flavorcrest peaches observed in figure 4 could be primarily explained by a drastic reduction in the percentage of fruit packed in the smallest fruit-size lug category (80s) (fig. 5). However, the change observed in Elegant Lady and O'Henry was mostly related to an increase in the percentage of fruit packed in the largest fruit-size lug category (30s) (fig. 5). Although industrywide data on fruit packed per acre is not available for these cultivars, one practical implication of these results is that the average yield of packed fruit has likely declined over the same 20-year period, since, on average, fruit size is generally correlated with crop load (Naor et al. 1999).

For example, a California thinning study showed a substantial effect on yield for both O'Henry and Elegant Lady (Johnson and Handley 1989). For O'Henry, the change in lug size from 1985 to 2004 (fig. 5) required average fruit weights to increase from 0.48

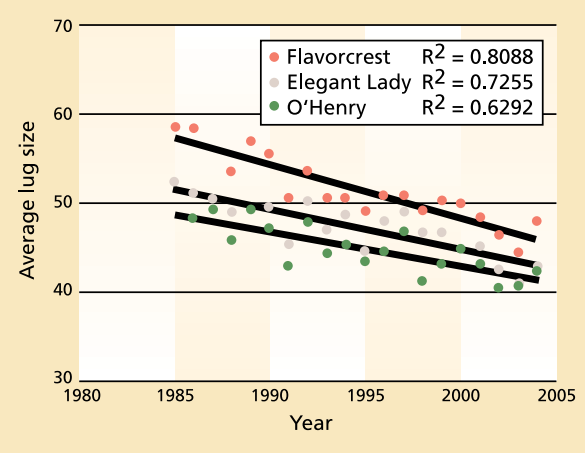

Fig. 4. Year and average fruit-size lugs packed in fresh-market freestone peaches.

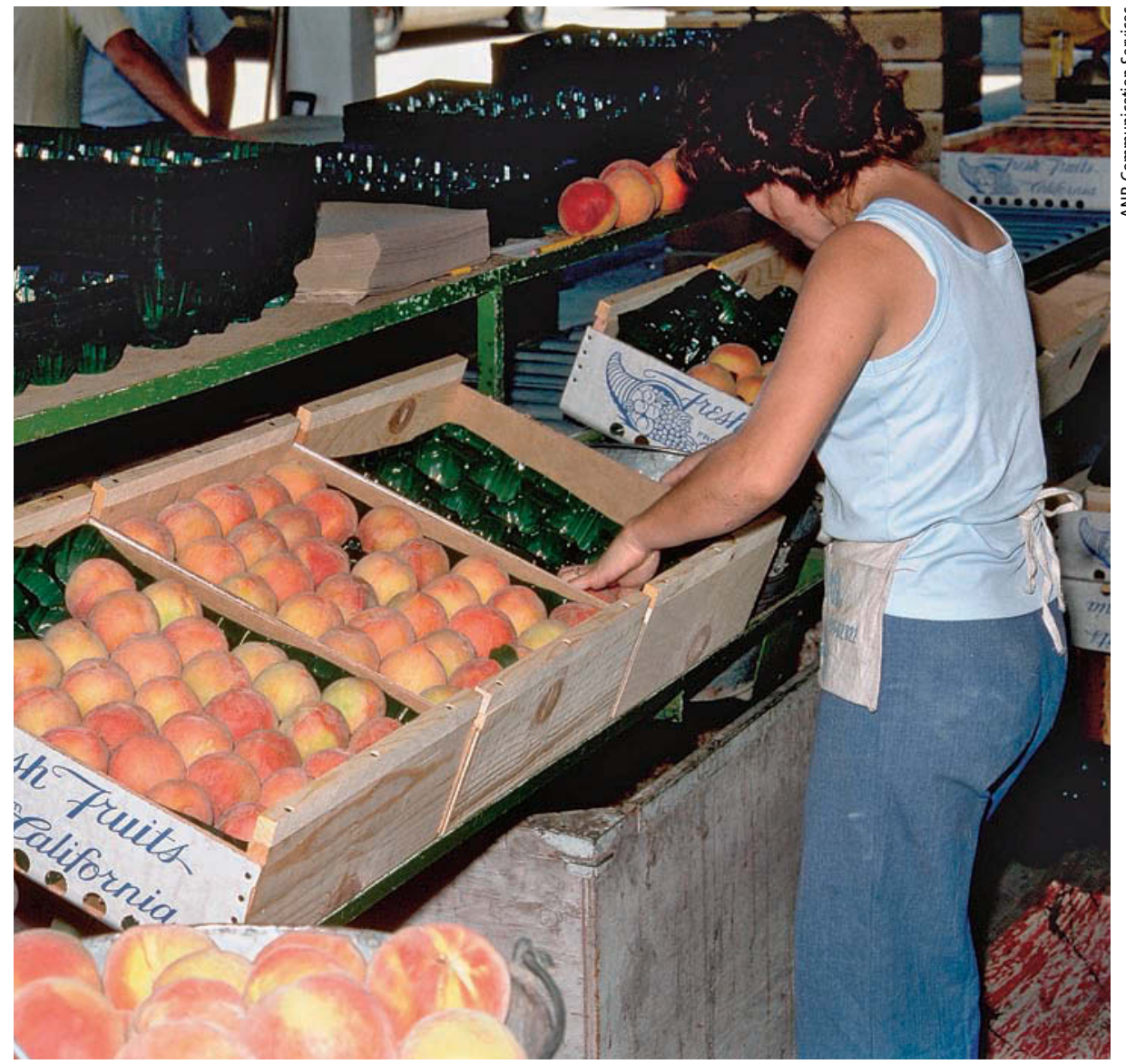

Between 1985 and 2004, the average size of fresh-market freestone peaches increased significantly, primarily due to consumer preferences for larger-sized fruit.

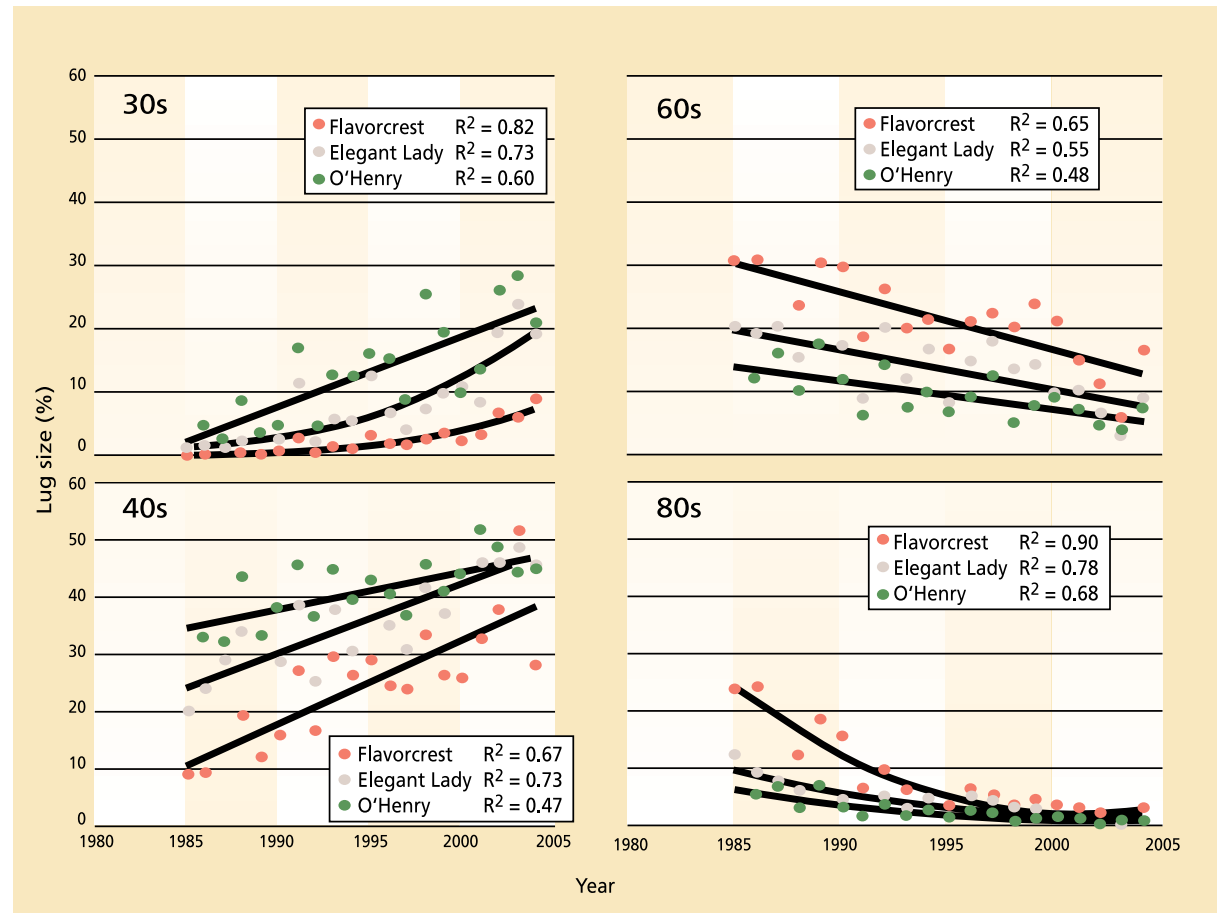

Fig. 5. Year and percentage lugs in four fruit-size lug categories of fresh-market freestone peaches $(30 s, 40 s, 60 s$ and $80 s)$. The relationships between year and percentage of lugs per each fruit-size category were fit to linear or polynomial equations. 


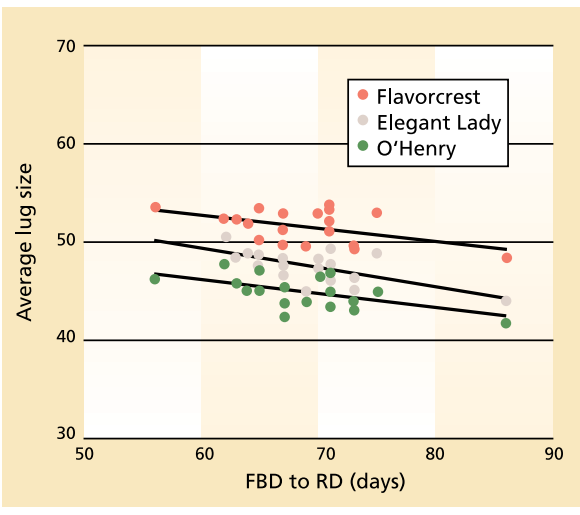

Fig. 6. Days from full bloom to reference date (FBD to RD) for the Kingsburg area, available from the canning clingstone peach industry, and the average adjusted fruit-size lug at harvest in fresh-market freestone peaches, after normalizing the average fruit-size lug data to the long-term industry trends in fig. 4.

pound (216 grams) to 0.56 pound (253 grams). To obtain these fruit weights, a typical tree would need to be thinned to 976 and 523 fruit in 1985 and 2004, respectively. Thus, yields would have dropped from 464 pounds per tree (211 kilograms) to 291 pounds per tree (132 kilograms), a 37\% decrease over the 20 years. The results for Elegant Lady were similar. However, the profitability of early cultivars such as Flavorcrest was probably affected more by market pressures than Elegant Lady and O'Henry, since decreases in the amount of fruit in smallsize categories were not offset as much by increases in fruit packed in the large-size categories (fig. 5).

When the data in figure 4 was used to normalize the fruit-size lug data to account for the long-term general trend, the deviation of a given year's average fruit-size lug category from the longterm trend was clearly related to spring weather patterns. The average, longterm, trend-adjusted fruit-size lug category for the fresh-market cultivars in a given year decreased, with an increase in the number of days of fruit growth between full bloom and reference date recorded in the same year for clingstone peaches (fig. 6). Although the variability in this relationship among the different cultivars could have been related to the inherent variability in sources of fruit that were packed, the similarity of the slopes of the relationships for the three

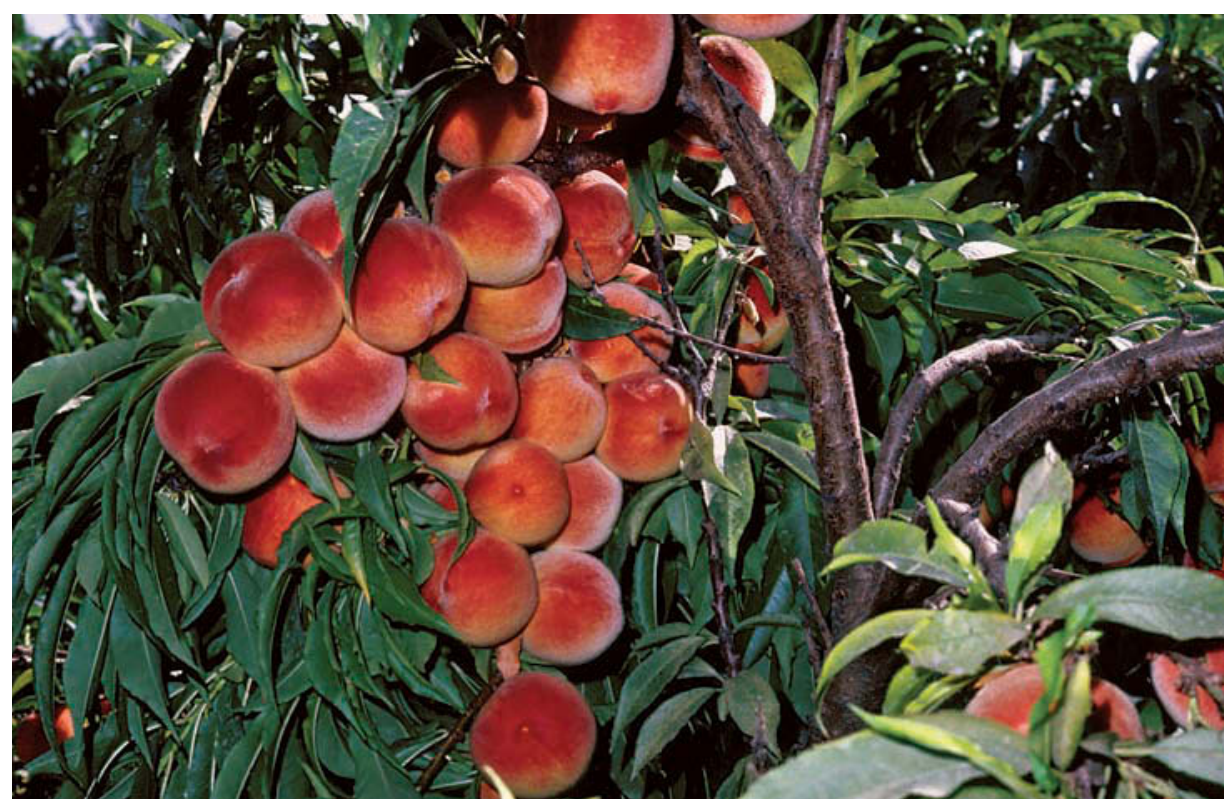

In order to accommodate the market for larger peaches, growers can utilize data on early-spring temperatures to predict potential fruit sizes at harvest, and make adjustments to cultural practices such as fruit thinning.

cultivars indicates that the conditions driving the relationships were likely similar for all three cultivars (fig. 6).

\section{Practical implications}

Previous research with clingstone peaches, combined with this analysis of fresh-market peach data, indicate that early fruit development rates are clearly related to heat accumulation, and that high early-spring temperatures tend to decrease the average size of fruit packed in a given year. This is apparently because in especially warm springs, the tree cannot supply resources rapidly enough to support the potential fruit growth rates associated with high rates of phenological development.

The relationships between fruit developmental patterns, fruit growth potentials and spring temperatures are even more important in light of the clear long-term marketing trends toward packing larger-sized fruit. Grower success will depend upon the ability to anticipate yearly fruit-sizing potential for individual cultivars and make the appropriate, cost-effective adjustments in cultural practices. It is well documented that early and heavy fruit thinning can increase average fruit size, but may cost more and/or reduce overall yields (Grossman and DeJong 1995a; DeJong et al. 1992). However, these practices may be particularly useful in difficult fruitsizing years in light of the increasing market pressure for large-size fruits.
G. Lopez is Graduate Student, Institut de Recerca i Tecnologia Agroalimentàries (IRTA), Àrea de Tecnologia Frutícola, Centre UdL-IRTA, Lleida, Spain; R.S. Johnson is Extension Specialist, and T.M. DeJong is Professor, both in the Department of Plant Sciences, UC Davis. Author G. Lopez received a FPI grant from the Spanish Ministry of Research and Technology (MCYT) to visit UC Davis.

\section{References}

Ben Mimoun M, DeJong TM. 1999. Using the relation between growing degree hours and harvest date to estimate run-times for PEACH: A tree growth and yield simulation model. Acta Hort 499:107-14.

Crisosto CH, Johnson RS, DeJong TM, Day KR. 1997 Orchard factors affecting postharvest stone fruit quality. Hortsci 32:820-3.

Crisosto CH, Mitchell FG, Johnson S. 1995. Factors in fresh market stone fruit quality. Postharvest News Info 6(2):17-21

DeJong TM. 2005. Using physiological concepts to understand early spring temperature effects on fruit growth and anticipating fruit size problems at harvest. Summerfruit 7:10-3.

DeJong TM, Andris H, Beede R, et al. 1992. Feasibility of increasing cling peach yields by early thinning. Cling Peach Research Report, California Cling Peach Board, Sacramento, CA. 9 p

Grossman YL, DeJong TM. 1995a. Maximum fruit growth potential and seasonal patterns of resource dynamics during peach growth. Ann Bot 75:553-60.

Grossman YL, DeJong TM. 1995b. Maximum fruit growth potential following resource limitation during peach growth. Ann Bot 75:561-7.

Johnson RS, Handley DF. 1989. Thinning response of early, mid-, and late-season peaches. J Am Soc Hort Sci 114(6):852-5.

Lopez G, DeJong TM. 2007. Spring temperatures have a major effect on early peach fruit growth. J Hort Sci Biotech. In press.

Naor A, Klein I, Hupert H, et al. 1999. Water stress and crop level interactions in relation to nectarine yield, fruit size distribution and water potentials. J Am Soc Hort Sci 124:189-93. 